\title{
EXPERIMENTAL MALARIA IN MAN. I. PHYSICAL DETERIORATION AND RECOVERY ${ }^{1}$
}

\author{
BY AUSTIN HENSCHEL, HENRY LONGSTREET TAYLOR, AND ANCEL KEYS \\ (From the Laboratory of Physiological Hygiene, University of Minnesota, Minneapolis)
}

(Received for publication July 22, 1949)

\section{INTRODUCTION}

It is generally recognized that a variety of stresses-environmental, nutritional, biologicalproduce physical deterioration and that recovery is not immediate upon the removal of the debilitating stress. In general, there are few quantitative data on the physical deterioration produced by stress and almost none on the recovery process, the principal exceptions being the stresses of brief severe work, exposure to heat, and some of the stresses related to high altitude. To these may be added the stress of prolonged caloric undernutrition which we have recently studied in some detail (Keys et al. [1] ; Henschel et al. [2] ; Simonson et al. [3] ; Franklin et al. [4] ; Schiele and Brozek [5] ; Taylor et al. [6]).

Physical deterioration may be estimated from changes in functional characteristics in rest, the response to performance tasks and from the actual performance under test conditions. Some of the requirements for making such measurements have been presented elsewhere (Taylor and Brozek [7]) and their application to a particular nutritional problem has been discussed (Keys [8]). Basically, questions must be asked as to what physiological characteristics are altered, how these changes are brought about, and how the total functional picture is reflected in actual performance. For any realistic application to the common situations met by man, it is clear that only data on man himself can have quantitative meaning.

With this viewpoint we have attempted to sample, in controlled experiments on young men, a few stresses of varied types including a toxic febrile state (malaria), and acute starvation (fasting) with and without physical work, lack of sleep, and bed rest. In general, the method has been to

\footnotetext{
1 The results reported here were obtained in part under a contract, recommended by the Committee on Medical Research, between the Regents of the University of Minnesota and the Office of Scientific Research and Development.
}

study the test subjects during a prolonged period of standardization and control before the imposition of the stress, and to repeat the tests and measurements at intervals during (if practical) and following the removal of the primary stress. The present article presents the major findings in malaria experimentally induced in previously healthy, "normal" young men.

\section{SUBJECTS}

The subjects were 12 young men from Civilian Public Service who were selected from volunteers and who specifically agreed to undergo the malaria stress. They resided in this laboratory and had all their meals here throughout a period of 12 months, during which time they actively cooperated in all phases of the research program. At the outset, and again at the conclusion of the work, careful physical examinations failed to reveal any physical defects or peculiarities of consequence; they were judged to be healthy, normal, young men.

In age they varied from 20 to 33 years, in height from 166.9 to $183.8 \mathrm{~cm}$., and in weight from 64.2 to $76.4 \mathrm{~kg}$. In activity habitus they varied from moderately active to rather sedentary; none was a real athlete and none was remarkably inactive.

\section{CONDITIONS AND PROGRAM}

After a pre-febrile control period of four weeks of standardized activity and diet, each subject was inoculated with the McCoy strain of Plasmodium vivax by the intravenous injection of $3 \mathrm{cc}$. of infected blood. Malaria developed in all cases. With the onset of the first paroxysm and during each subsequent paroxysm the subjects were confined to bed and provided with medical and nursing care. Rectal temperature, pulse rate, respiration rate and blood pressure were charted at half-hour intervals during the paroxysms and at two-hour intervals during the remission periods. Water intake was maintained at more than $3,000 \mathrm{cc}$. daily and the standard diet (3,600 Cal. with 85 gms. protein) was offered although food consumption dropped off somewhat during the febrile periods. Codeine was given as needed to control headaches. The subjects were allowed short periods of limited activity out of bed during the afebrile stages of the malaria. After five to eight paroxysms and an average of 193 degree-hours of temperature above $101^{\circ} \mathrm{F}$. the malaria was terminated without incident with quinine 
sulphate. Ferrous sulphate $(0.4 \mathrm{gm}$. daily $)$ was started with the quinine and continued for five weeks.

On the morning of the third day following the last paroxysm the subjects were returned to the standard activity routine which had been maintained in the control period. The standard activity consisted of routine work around the laboratory plus one hour daily of walking on a motor-driven treadmill at 3.5 miles per hour on a 10 per cent grade; short (three to five minutes) work periods of maximum intensity were included every few days. In the testing rooms the temperature was maintained at $78^{\circ} \mathrm{F}$. and relative humidity at 50 per cent of saturation. The functions tested were followed at frequent intervals until they had returned to or approached the control values.

\section{METHODS}

Hemoglobin concentration was determined daily as alkaline oxyhemoglobin in basal venous blood drawn from an antecubital vein and delivered to the Sahli pipette from the syringe without any anticoagulant. Plasma and total blood volumes were estimated by the dye dilution (T-1824) method of Gibson and Evans (9), and Gibson and Evelyn (10). Heparinized blood for hematocrit readings was centrifuged in Wintrobe hematocrit tubes for one hour at 3,000 rpm.

The work test of moderate intensity involved a 60 minute walk on a motor-driven treadmill at 3.5 miles per hour on a 10 per cent grade. Pulse rates were counted with a stethescope for 15-second intervals at 55, 58 and 60 minutes of the work, and these were averaged to represent the work pulse rate. The recovery pulse rates are the average of the rates measured at $60-75$ and 120 135 seconds of standing recovery following the 60-minute walk. Expired air was collected in a balanced gasometer from 54 to 59 minutes of the walk; this was analyzed for oxygen and carbon dioxide content with the Haldane apparatus.

The maximal oxygen intake was determined for the 1.75 to 2.75 minutes of $a$ three-minute run on the motordriven treadmill at 7 miles per hour on grades of 2.5 to 7.5 per cent adjusted to each subject's capacity. During the pre-malaria control period each subject was standardized at two grades of work differing by 2.5 per cent which agreed for maximal oxygen consumption values. The post-malaria grade was in all cases the lower of the two control grades.

Venous blood was drawn for lactate and pyruvate concentration analysis at the end of a five-minute rest following a 30-minute walk at 3.5 miles per hour on a 10 per cent grade (standard rest sample), and at 12 minutes following the three-minute runs. Measured amounts of the blood were delivered directly from the syringe into cold trichloracetic acid and the filtrate was analyzed for lactate by the method of Edwards (11) and for pyruvate by the method of Friedemann and Haugen (12).

Maximum endurance for severe work was determined by the Harvard Fitness Test (Johnson et al. [13]) which consists of running on a motor-driven treadmill at
7 miles per hour on an 8.6 per cent grade until complete exhaustion or for five minutes. Pulse rates were counted from one to one and a half, two to two and a half, and four to four and a half minutes of seated recovery. The scoring system (op. cit.) includes time of run and recovery pulse rate components and presumably includes circulatory, respiratory, muscular and motivation elements.

The response of the heart rate and blood pressure to a change from the horizontal to the tilted $\left(68^{\circ}\right)$ body position was used as an index of postural cardiovascular stability before and following malaria. The tilt-table was equipped with a footboard. The scoring system described by Crampton (14) was employed.

The urinary excretion of 17-ketosteroids was determined by the method of Miller and Mickelsen (15) and Miller, Mickelsen and Keys (16) for seven of the subjects before malaria, during paroxysms and for afebrile periods between paroxysms.

\section{RESULTS}

\section{Blood morphology}

The data for blood hemoglobin concentration on representative days before, during and following the experimental malaria are given in Table I. The expected progressive decrease in blood hemoglobin concentration occurred with an average loss of 2.4 gms. per $100 \mathrm{cc}$. of whole blood (15.9 per cent) during the course of the febrile process.

TABLE I

Basal hemoglobin concentration in gms. per $100 \mathrm{cc}$. of whole blood before, during and following experimental malaria

\begin{tabular}{|c|c|c|c|c|c|c|c|c|c|c|}
\hline \multirow{2}{*}{ Item } & \multirow{2}{*}{$\begin{array}{l}\text { Con- } \\
\text { trol }\end{array}$} & \multicolumn{2}{|c|}{ Febrile day } & \multicolumn{7}{|c|}{ Post-febrile day } \\
\hline & & 5 & 8 & 1 & 5 & 8 & 11 & 15 & 18 & 28 \\
\hline $\begin{array}{l}\text { Mean } \\
\text { S.D. }\end{array}$ & $\begin{array}{c}15.1 \\
0.78\end{array}$ & $\begin{array}{r}14.1 \\
0.92\end{array}$ & $\begin{array}{l}13.5 \\
0.94\end{array}$ & $\begin{array}{c}12.7 \\
1.03\end{array}$ & $\begin{array}{c}11.8 \\
1.12\end{array}$ & $\begin{array}{r}12.5 \\
1.11\end{array}$ & $\begin{array}{c}13.2 \\
1.32\end{array}$ & \begin{tabular}{|c|}
13.5 \\
1.17
\end{tabular} & $\begin{array}{c}14.2 \\
1.25\end{array}$ & $\begin{array}{r}14.7 \\
1.18\end{array}$ \\
\hline
\end{tabular}

An additional loss of $0.9 \mathrm{gm}$. per $100 \mathrm{cc}$. of blood took place during the first five fever-free days after the introduction of quinine therapy. From that time on the regeneration of hemoglobin was accomplished at a rate of about $1 \mathrm{gm}$. per $100 \mathrm{cc}$. of blood per week. By the end of the fourth postfebrile week (28 days) the average hemoglobin concentration was only slightly below the control values. Complete return to the pre-malaria control value of 15.1 gms. per $100 \mathrm{cc}$. of whole blood was not achieved until five weeks after the termination of the malaria.

Blood volume estimations were made before inoculation and on the second post-febrile day. The 
essential data are presented in Table II. There was no significant change in the plasma volume either as total or cc. per $\mathrm{kg}$. of body weight during the course of the malaria. The reduction in the total blood volume reflected the changes in the hematocrit and red cell volume.

TABLE II

Mean blood volume data before and 24 hours after the termination of experimental malaria

\begin{tabular}{|c|c|c|c|c|}
\hline \multirow{2}{*}{ Item } & \multicolumn{2}{|c|}{ Before } & \multicolumn{2}{|c|}{ After } \\
\hline & Mean & S.D. \pm & Mean & S.D. \pm \\
\hline $\begin{array}{l}\text { Plasma vol., cc. } \\
\text { Hematocrit, per cent } \\
\text { Red cell vol., cc. } \\
\text { Total blood vol., cc. } \\
\text { Hemoglobin, gms. }\end{array}$ & $\begin{array}{l}3383 \\
44.7 \\
2735 \\
6118 \\
15.1\end{array}$ & $\begin{array}{l}287 \\
3.0 \\
386 \\
649 \\
0.78\end{array}$ & $\begin{array}{l}3365 \\
39.6 \\
2207 \\
5572 \\
12.7\end{array}$ & $\begin{array}{l}307 \\
3.5 \\
346 \\
586 \\
1.03\end{array}$ \\
\hline
\end{tabular}

\section{The response to work}

The pulse rate response to the standard work test of moderate intensity was substantially increased following malaria. The data for the work and recovery pulse rates are given in Table III. On the first day the subjects did the work test following recovery from malaria (third postfebrile day) the average work pulse rate was 26.9 beats per minute (21.4 per cent) and the average recovery pulse rate 29.7 beats ( 31.0 per cent) higher than during the control period. A general progressive decline toward normal in both work and recovery pulse rates occurred with time. At the 22nd afebrile day the work and recovery pulse rates were still slightly elevated (significant at the 5 per cent level); two days later the pulse rates were essentially normal. It is interesting that an average work pulse rate difference of only 3 beats per minute was statistically significant at the 5 per cent level (22nd post-febrile day); this indicates the high degree of consistency achieved in these studies. The return of the work and re- covery pulse rates to normal did not, however, progress in a smooth linear fashion. No apparent improvement occurred between post-febrile days 5 and 7,9 and 11 , and 13 and 17. At one pointthe 11 th day-the recovery pulse rates were significantly higher than at any time after the third day. The absolute difference between the work and recovery pulse rates remained substantially constant in the control and post-febrile periods, although the percentage difference was greater when the subjects were more normal.

The oxygen consumption, ventilation, respiratory efficiency (cc. oxygen removed per liter of ventilation) and mechanical efficiency during work of moderate intensity were not altered by the malaria; oxygen consumption was decreased 12 cc. per minute, ventilation increased 1.44 liters per minute and respiratory efficiency decreased $1.9 \mathrm{cc}$. per liter on the third afebrile day. Except for the work and recovery pulse rates, this moderate work test apparently was not sufficiently strenuous to elicit other signs of deterioration, particularly of the muscular and respiratory systems.

Under the stress of the maximal oxygen intake test (three-minute run at 7 miles per hour on a 2.5 to 7.5 per cent grade) the deterioration of the cardiovascular-respiratory systems during malaria was clearly demonstrated. As indicated in Table IV, the ventilation increased 12.5 per cent, the oxygen consumption decreased 18.9 per cent and the respiratory efficiency decreased 22.5 per cent during the febrile period. Recovery of these functions was slow but progressive during the subsequent post-febrile weeks. At the end of the fourth post-febrile week a little over half of the deterioration which had occurred during the malaria had been regained $(56.8,58.7$ and 55.4 per cent for ventilation, oxygen consumption, and respiratory efficiency, respectively). Early in the sixth post-febrile week ventilation was the only one of these functions that had not returned to

TABLE III

Pulse rates, beats per minute, during an hour's walk at 3.5 miles per hour on a 10 per cent grade and seated recovery, before and for 22 days following experimental malaria

\begin{tabular}{|c|c|c|c|c|c|c|c|c|c|}
\hline Item & Control & 3 & 5 & 7 & 9 & 11 & 13 & 17 & 22 \\
\hline $\begin{array}{l}\text { Work, Mean } \\
\text { Work, S.D. } \\
\text { Recovery, Mean } \\
\text { Recovery, S.D. }\end{array}$ & $\begin{array}{r}125.6 \\
9.6 \\
95.6 \\
13.0\end{array}$ & $\begin{array}{r}152.5 \\
18.4 \\
125.3 \\
16.5\end{array}$ & $\begin{array}{r}138.5 \\
10.2 \\
105.6 \\
10.4\end{array}$ & $\begin{array}{r}138.8 \\
10.5 \\
107.0 \\
15.6\end{array}$ & $\begin{array}{r}134.6 \\
8.2 \\
105.3 \\
14.9\end{array}$ & $\begin{array}{r}134.7 \\
8.1 \\
111.6 \\
26.6\end{array}$ & $\begin{array}{r}130.1 \\
9.8 \\
101.3 \\
14.6\end{array}$ & $\begin{array}{c}131.6 \\
10.30 \\
105.8 \\
16.1\end{array}$ & $\begin{array}{r}128.5 \\
8.3 \\
102.2 \\
13.8\end{array}$ \\
\hline
\end{tabular}


TABLE IV

Maximal oxygen transport, ventilation and respiratory efficiency before and following experimental malaria

\begin{tabular}{|c|c|c|c|c|c|c|}
\hline \multirow{2}{*}{ Date } & \multicolumn{2}{|c|}{$\begin{array}{c}\text { Ventilation } \\
\text { liters per minute }\end{array}$} & \multicolumn{2}{|c|}{$\begin{array}{l}\text { Oxygen used } \\
\text { liters per minute }\end{array}$} & \multicolumn{2}{|c|}{$\begin{array}{l}\text { Respiratory } \\
\text { efficiency }\end{array}$} \\
\hline & Mean & S.D. & Mean & S.D. & Mean & S.D. \\
\hline $\begin{array}{l}\text { Pre-malaria } \\
\text { Fifth afebrile day } \\
\text { Seventh afebrile day } \\
\text { Ninth afebrile day } \\
\text { 15th afebrile day } \\
21 \text { st afebrile day } \\
\text { 26th afebrile day }\end{array}$ & \begin{tabular}{r|}
91.07 \\
102.45 \\
102.59 \\
100.24 \\
97.84 \\
95.99 \\
95.98
\end{tabular} & $\begin{aligned} 11.73 \\
9.32 \\
8.47 \\
8.65 \\
9.17 \\
8.09 \\
8.67\end{aligned}$ & $\begin{array}{l}3.639 \\
2.953 \\
3.020 \\
3.065 \\
3.138 \\
3.252 \\
3.356\end{array}$ & $\begin{array}{l}0.283 \\
0.213 \\
0.204 \\
0.218 \\
0.248 \\
0.243 \\
0.237\end{array}$ & $\begin{array}{l}40.2 \\
29.0 \\
27.0 \\
30.8 \\
32.3 \\
34.1 \\
35.2\end{array}$ & $\begin{array}{l}4.97 \\
5.92 \\
8.62 \\
3.25 \\
5.46 \\
8.16 \\
1.39\end{array}$ \\
\hline
\end{tabular}

the pre-malaria control values; it was still significantly elevated (at the 5 per cent level).

The treadmill version of the Harvard Fitness Test was employed as a measure of maximum physical performance and endurance. The test was administered before and at four, six and eight weeks following the experimental malaria. The mean fitness scores and time of runs for the 12 subjects are given in Table V. At the fourth post-febrile week the fitness score and time of run were only 82.5 and 87.9 per cent, respectively, of the pre-malaria control values. Two weeks later (at six weeks when the maximal oxygen intake and respiratory efficiency were normal) both the score and time of run were still. significantly reduced ( 1 per cent level of significance). Recovery was apparently complete at eight weeks after the termination of the experimental malaria; at that time there was no statistically significant difference from the control value.

\section{Blood lactate and pyruvate}

The deteriorative changes induced by the malaria were reflected in the blood lactate and pyruvate concentrations, both in standard rest and 12 minutes after severe exercise. The data are sum-
TABLE V

The score and the length of run in seconds on the Harvard Fitness Test (treadmill version) before and at four, six and eight weeks after experimental malaria

\begin{tabular}{|c|c|c|c|c|c|c|c|c|}
\hline \multirow{2}{*}{ Item } & \multicolumn{2}{|c|}{ Control } & \multicolumn{2}{|c|}{$\begin{array}{l}\text { Four weeks } \\
\text { after }\end{array}$} & \multicolumn{2}{|c|}{$\begin{array}{c}\text { Six weeks } \\
\text { after }\end{array}$} & \multicolumn{2}{|c|}{$\begin{array}{l}\text { Eight weeks } \\
\text { after }\end{array}$} \\
\hline & Time & Score & Time & Score & Time & Score & Time & Score \\
\hline $\begin{array}{l}\text { Mean } \\
\text { S.D. }\end{array}$ & $\begin{array}{r}229.7 \\
63.5\end{array}$ & $\begin{array}{l}69.3 \\
19.2\end{array}$ & $\begin{array}{r}208.2 \\
73.5\end{array}$ & $\begin{array}{l}57.2 \\
17.6\end{array}$ & $\begin{array}{r}211.1 \\
71.3\end{array}$ & $\begin{array}{l}60.8 \\
20.6\end{array}$ & $\begin{array}{r}224.3 \\
70.7\end{array}$ & $\begin{array}{l}65.3 \\
20.6\end{array}$ \\
\hline
\end{tabular}

marized in Table VI. On the fifth post-febrile day the standard rest and the 12-minute lactates were increased by 56.2 and 101.9 per cent, respectively. Both were still significantly increased at 18 days but were back to normal by the sixth post-malaria week. The standard rest pyruvate was elevated on only the fifth post-febrile day.

At no time, either at rest or after maximal work, did the blood pyruvate concentration increase relatively as much as did the lactate. As a result, all lactate-pyruvate ratios were elevated (Table VI). Normally, the lactate-pyruvate ratio is higher after hard physical work than at rest and increases with an increase in the intensity of the work task. It would therefore be reasonable to expect that under conditions of deterioration in physical performance capacity, as malaria, the lactate-pyruvate ratio would be elevated, particularly so because the maximal oxygen intake test more closely approached the maximal performance capacity of the subjects after malaria than it did during the control period. The post-febrile runs were, however, made on the lower of the two control period grades that produced maximal oxygen consumptions.

\section{Postural adjustment}

The cardiovascular response to a change from the horizontal to a tilted $\left(68^{\circ}\right)$ body position is

TABLE VI

Blood lactate and pyruvate in mgs. per $100 \mathrm{cc}$. of whole blood at standard rest and 12 minutes after anaerobic work before and at five, seven and 18 days after experimental malaria

\begin{tabular}{|c|c|c|c|c|c|c|c|c|}
\hline \multirow{2}{*}{ Item } & \multicolumn{2}{|c|}{ Before } & \multicolumn{2}{|c|}{ Five days after } & \multicolumn{2}{|c|}{ Seven days after } & \multicolumn{2}{|c|}{18 days after } \\
\hline & Rest & $12 \mathrm{~min}$. & Rest & $12 \mathrm{~min}$. & Rest & $12 \mathrm{~min}$. & Rest & $12 \mathrm{~min}$. \\
\hline $\begin{array}{l}\text { Lactate, Mean } \\
\text { Lactate, S.D. . } \\
\text { Pyruvate, Mean } \\
\text { Pyruvate, S.D. } \pm \\
\text { LA/PA rates }\end{array}$ & $\begin{array}{l}6.69 \\
1.60 \\
1.15 \\
0.19 \\
5.82\end{array}$ & $\begin{array}{r}39.61 \\
17.16 \\
3.44 \\
0.93 \\
11.51\end{array}$ & $\begin{array}{r}10.44 \\
3.34 \\
1.28 \\
0.21 \\
8.16\end{array}$ & $\begin{array}{r}80.00 \\
18.60 \\
5.02 \\
0.83 \\
15.94\end{array}$ & $\begin{array}{r}10.58 \\
3.88 \\
1.17 \\
0.22 \\
9.04\end{array}$ & $\begin{array}{r}73.22 \\
28.39 \\
4.79 \\
0.84 \\
15.29\end{array}$ & $\begin{array}{l}8.73 \\
2.10 \\
1.19 \\
0.19 \\
7.34\end{array}$ & $\begin{array}{r}54.45 \\
18.52 \\
4.13 \\
0.64 \\
13.22\end{array}$ \\
\hline
\end{tabular}




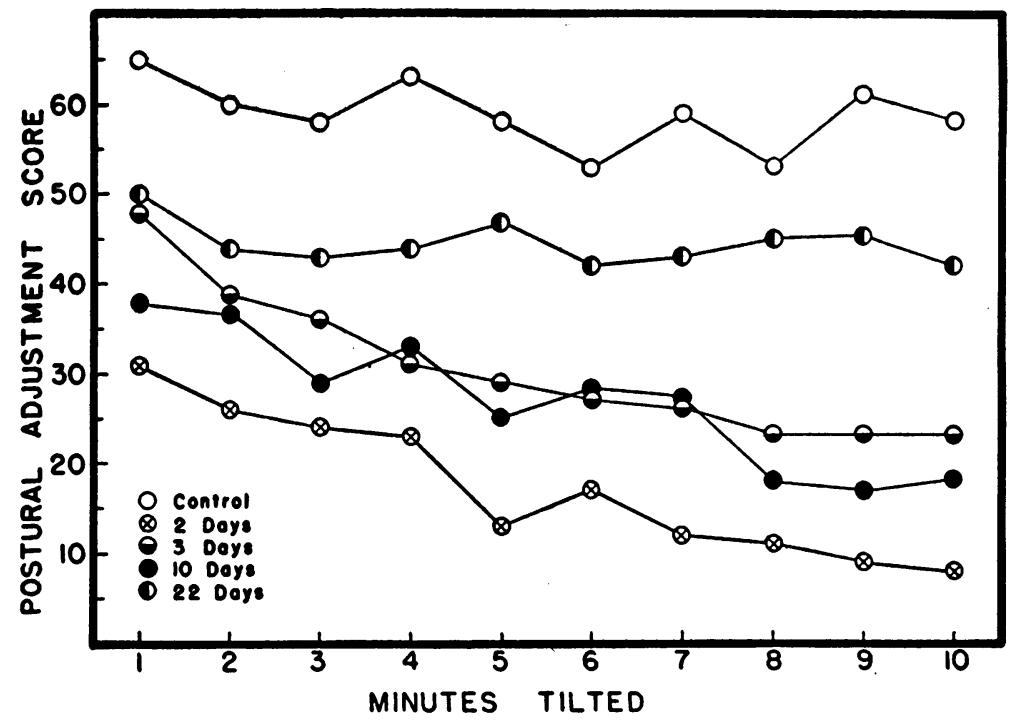

Fig. 1. Postural Adjustment Score for Each of the Ten Minutes of Tilted Position Before and at Two, Three, Ten and 22 Days after Experimental Malaria

illustrated for the pre- and post-malaria periods in Figure 1. Here the postural adjustment scores are plotted for each of the ten minutes that the subjects were tilted during the test; the scores were calculated from Crampton's tables (14). A group mean score for each testing period was derived from the mean minute scores plotted in Figure 1. The mean scores were $58.8 \pm 12.7,17.4 \pm$ $16.5,26.9 \pm 17.0,27.0 \pm 17.3$ and $44.5 \pm 15.4$ on the control and two, three, ten and 22 post-febrile days, respectively. The ability of the cardiovascular system to adjust to the tilted position showed striking deterioration during the febrile period. The recovery of the function was very slow, especially during the first ten post-febrile days; actually no recovery occurred for the period of the third to tenth afebrile days.

Of particular interest is the course of the adjustment scores during the ten minutes of tilting. In the control period, although there was a variation of as much as ten points from one minute to another, the general trend of the curve was horizontal. At two, three and ten days after malaria the scores were satisfactorily high during the first and second minutes of tilting but after the second minute they decreased progressively so that poor adjustments were found during the last minutes of the test. By the end of three weeks of rehabilitation the minute-to-minute score curve had the same horizontal trend as in the control period even though the absolute scores were still low; the group mean scores at 22 days were below the control score and this was significant at the 5 per cent level.

In the control period none of the subjects experienced any difficulty in adjusting to the ten minutes of tilting. On the second post-febrile day one subject fainted after being tilted for four minutes and one subject complained of dizziness at nine minutes. The other ten subjects experienced no strong symptoms of approaching syncope but diastolic blood pressures became difficult to measure in five of the subjects during the test. After the second day no fainting or dizziness occurred and no subjective symptoms were recorded in spite of the fact that the adjustment scores showed only small improvement until after the tenth postfebrile day.

\section{7-Ketosteroid excretion}

The data for the effects of malaria on the urinary excretion of 17 -ketosteroids are given in Table VII. Because of difficulties in obtaining properly timed samples in both febrile and afebrile periods, the data are limited to seven of the 12 subjects.

The mean control excretion of 473 micrograms of 17-ketosteroids per hour (11.5 mgs. per day) 
TABLE VII

Urinary excretion of total 17-ketosteroids in micrograms per hour as affected by malaria*

\begin{tabular}{c|c|c|c|c}
\hline \hline Subject & Control & N.F. & Fever & $\begin{array}{c}\text { Per cent } \\
\text { change }\end{array}$ \\
\hline 7 & 554 & 371 & 491 & -22 \\
8 & 516 & 341 & 301 & -38 \\
9 & 533 & 92 & 257 & -67 \\
11 & 400 & & 231 & -42 \\
15 & 379 & 218 & 384 & -21 \\
19 & 388 & & 347 & -11 \\
20 & 538 & 241 & 277 & -52 \\
Mean & 473 & 253 & 327 & -36 \\
\hline
\end{tabular}

* Control values are the means for the individuals at various times before and some months after the malaria. "N.F." indicates the values in the non-febrile state between paroxysms. "Fever" indicates the values in the febrile state with a rectal temperature above $100^{\circ} \mathrm{F}$. All values in micrograms per hour. "Per cent Change" indicates the difference between the control and the mean of Fever and N.F.

for the group of seven subjects was similar to the excretions previously reported for normal young men (Miller, Mickelsen and Keys [16]). Except for subject No. 15, the 17-ketosteroid excretion was depressed by from 41 to 275 micrograms per hour during the periods when the body temperature was above $100^{\circ} \mathrm{F}$. In four of the five subjects on whom samples were obtained during the afebrile state between paroxysms, the depression of $17-$ ketosteroid excretion was greater than in the febrile periods. The data are, however, too few to decide whether the urinary excretion of the 17-ketosteroids is depressed more in the febrile than in the afebrile periods of malaria. In any event, the 24-hour excretion of the 17ketosteroids was depressed from 11 to 67 per cent during the course of experimental malaria in all cases.

\section{DISCUSSION}

A comparison of the "per cent deterioration" of the physiological and biochemical functions involved in the response to a stress situation is both unrealistic and futile. There are no observations and facts that allow one to judge the relative departure from normal function of, for example, a 10 per cent decrease in hemoglobin concentration as compared to a 10 per cent decrease in maximal oxygen intake. It is then without value to attempt to estimate the relative degree of deterioration of the various systems that occurred during experimental malaria. From the results of the battery of tests used it is apparent, however, that some systems were affected rather seriously while other systems appeared to remain normal.

The data show that during malaria destruction of red blood cells occurred with a resulting hypochromic anemia but the plasma volume was unchanged. Electrophoretic pattern shifts characteristic of other infectious diseases were observed in the plasma proteins (Taylor, Mickelsen and Keys [6]).

Of particular interest is the possible relationship between the decreased blood hemoglobin concentration and the increased work pulse rates that were observed following the malaria. At the fifth post-febrile day the hemoglobin concentration was 21.9 per cent below the control value and the work pulse rates were increased 10.3 per cent. The increased pulse rate would tend to compensate for the decreased hemoglobin concentration so that the oxygen delivered to the tissue per unit time would be normal. Some indication of this can be obtained from the circulatory index; this is the oxygen consumption per heart beat corrected for the oxygen capacity of the blood. On the fifth post-febrile day the circulatory index was 10.77 per cent above the control value; the index progressively decreased during convalescence and was essentially normal on the 18th day. The fact that the circulatory index increased indicates that the work pulse rate did not increase in proportion to the decline in blood hemoglobin concentration. The lack of demand for a higher work pulse rate might be the result of (1) an increased stroke volume, (2) an increased A-V oxygen difference and/or (3) the development of an oxygen debt.

The deterioration and recovery of the functions measured by the maximal performance capacity tests (maximal oxygen intake and Harvard Fitness Test) all followed the same general time sequence. The maximal oxygen intake test involves mainly the cardiovascular and respiratory systems while the Harvard Fitness Test, besides these two systems, also includes the muscles. Because of the similarity in the time sequence of recovery of the deterioration as measured by the two tests, it appears likely that the cardiovascular system was the major site of change during malaria and that the change in it was the major limiting factor to maximal physical performance fol- 
lowing the disease. The large deterioration in the ability to adjust to the upright posture strengthens the view that many of the changes induced by the experimental malaria were cardiovascular in nature.

The reduction in the urinary excretion of the 17-ketosteroids is contrary to what would be expected from some reports in the literature which have emphasized that the ketosteroid excretion is increased in stress situations (Pincus [17]). However, the recent work of Miller, Mickelsen and Keys (16) has shown that in at least two situations involving both physical and emotional stress (acute starvation and semi-starvation) the 17-ketosteroid excretion is decreased by about 30 per cent. Experimental malaria must also be included among the stresses that decrease rather than increase the urinary excretion of the 17 ketosteroids.

It is possible to construct an approximate time table of recovery of the various functions measured following experimental malaria. The work and recovery pulse rates were the first items to return to normal; normality in these was regained at about three weeks. Hemoglobin concentration was recovered by the end of four weeks. The maximal oxygen consumption and respiratory efficiency during maximal work required four to six weeks to return to normal, while the ventilation rate was a little slower but was normal at six weeks. The maximal work capacity (Harvard Fitness Test) was significantly reduced at six weeks but was normal at eight weeks. Blood lactate and pyruvate concentration 12 minutes after maximal work were elevated at 18 days but were normal at six weeks. The cardiovascular adjustment to the upright posture required more than three weeks and less than seven weeks to recover. No data were obtained on the time required for the return to normal of the 17 -ketosteroid excretion.

\section{SUMMARY}

1. Malaria was induced in 12 normal young men by inoculation with $3 \mathrm{cc}$. of blood infected with the McCoy strain of Plasmodium vivax. The malaria was terminated with quinine sulphate after five to eight paroxysms and an average of 193 degree-hours of temperature above $101^{\circ} \mathrm{F}$.

2. Blood hemoglobin concentration was reduced an average of 3.3 gms. per $100 \mathrm{cc}$. of blood. To- tal plasma volume was not changed. Complete recovery of the hemoglobin required about four weeks.

3. The pulse rate during a work test of moderate severity was increased 26.9 beats per minute and recovery rate 29.7 beats per minute on the third post-febrile day; normal values were obtained three weeks after the malaria.

4. Maximal oxygen intake was decreased 18.9 per cent on the fifth post-febrile day. About six weeks were required for recovery of the function.

5. Maximal performance capacity as measured by the Harvard Fitness Test was depressed until the eighth post-febrile week.

6. Blood lactate concentration was increased 56.2 per cent at standard rest and 101.9 per cent 12 minutes after short exhausting work. Blood pyruvate concentration was increased 45.9 per cent after the hard work but the resting pyruvate concentration was not increased.

7. Cardiovascular stability as. measured by the tilt-table deteriorated about 50 per cent during the malaria but was essentially normal three or four weeks after the malaria.

8. The excretion of 17 -ketosteroids was depressed during the experimental malaria.

\section{ACKNOWLEDGMENTS}

This work would have been impossible without the active and intelligent cooperation of the Conscientious Objectors who volunteered to act as subjects: C. W. Baker, H. Browne, A. D. Butler, W. Cadbury, R. F. Landis, R. Mitchell, E. G. Nicholson, P. S. Olmsted, C. E. Patterson, T. Sandness, R. E. Seymour and W. Steinberger. Several other members of the Civilian Public Service Unit helped in the nursing and technical work. Clinical counsel and aid was given by Drs. Rodney Kendall, F. W. Hoffbauer, Henry E. Mickelson and Cecil J. Watson. Mrs. Angie Sturgeon Skinner supervised the assistant staff and aided all parts of the work.

\section{BIBLIOGRAPHY}

1. Keys, A., Henschel, A., and Taylor, H. L., The size and function of the human heart at rest in semistarvation and in subsequent rehabilitation. Am. J. Physiol., 1947, 150, 153.

2. Henschel, A., Mickelsen, O., Taylor, H. L., and Keys, A., Plasma volume and thiocyanate space in famine edema and recovery. Am. J. Physiol., 1947, 150, 170.

3. Simonson, E., Henschel, A., and Keys, A., The electrocardiogram of man in semi-starvation and rehabilitation. Am. Heart J., 1948, 35, 584. 
4. Franklin, J. C., Schiele, B. C., Brozek, J., and Keys, A., Observations on human behavior in experimental semi-starvation and rehabilitation. J. Clin. Psychol., 1948, 4, 28.

5. Schiele, B. C., and Brozek, J., "Experimental neurosis" resulting from semi-starvation in man. Psychasom. Med., 1948, 10, 31.

6. Taylor, H. L., Mickelsen, O., and Keys, A., The effects of induced malaria, acute starvation and semi-starvation on the electrophoretic diagram of the serum proteins of normal young men. J. Clin. Invest., 1949, 28, 273.

7. Taylor, H. L., and Brozek, J., Symposium on physiological aspects of convalescence and rehabilitation; evaluation of fitness. Federation Proc., 1944, 3, 216.

8. Keys, A., Human fitness and the state of vitamin nutrition. Nutrition Rev., 1947, 5, 129.

9. Gibson, J. G., 2nd, and Evans, W. A., Jr., Clinical studies of the blood volume. I. Clinical application of a method employing the azo dye "Evans Blue" and the spectrophotometer. J. Clin. Invest., 1937, 16, 301 .
10. Gibson, J. G., 2nd, and Evelyn, K. A., Clinical studies of the blood volume. IV. Adaptation of the method to the photoelectric colorimeter. J. Clin. Invest., 1938, 17, 153.

11. Edwards, H. T., A simplified estimation of lactate in normal human blood. J. Biol. Chem., 1938, 125, 571.

12. Friedemann, T. E., and Haugen, G. E., Pyruvic acid, determination of keto acids in the blood and urine. J. Biol. Chem., 1943, 147, 415.

13. Johnson, R. E., Brouha, L., and Darling, R. C., A practical test of physical fitness for strenuous exertion. Rev. Canad. Biol., 1942, 1, 491.

14. Crampton, C. W., The gravity resisting ability of the circulation; its measurement and significance. Am. J. M. Sc., 1920, 160, 721.

15. Miller, E. O., and Mickelsen, $O$. To be published.

16. Miller, E. O., Mickelsen, O., and Keys, A., Urinary excretion of 17-ketosteroids by normal young men during starvation. Proc. Soc., Exper. Biol. \& Med., 1948, 67, 288.

17. Pincus, G., Recent Progress in Hormone Research. Academy Press, Inc.; New York, 1947. 